\title{
Seria a Doença de Parkinson Fator Protetor da Enxaqueca?
}

\author{
Is Parkinson's Disease protective factor for migraine? \\ Celmir de Oliveira Vilaça ${ }^{1}$, Marco Antonio Araujo Leite', \\ Jano Alves de Souza ${ }^{3}$, João Santos Pereira ${ }^{4}$, Marco Orsini ${ }^{5}$
}

\section{RESUMO}

Objetivo. Realizar uma revisão sobre a participação das vias dopaminérgicas na enxaqueca e discutir a hipótese que a Doença de Parkinson (DP), ao provocar a degeneração das vias dopaminérgicas, poderia servir como fator protetor para enxaqueca. Método. Revisão não sistemática de artigos utilizando-se os unitermos: "dopamine", "migraine" e "Parkinson Disease". Priorizou-se artigos que contivessem a associação desses unitermos no título. Utilizou-se para a pesquisa as base de dados PubMed e Lilacs. Resultados. Foram escolhidos 32 artigos originais, 6 artigos de revisão e um manual. Conclusáo. A enxaqueca se caracteriza por um estado de aumento da atividade dopaminérgica no sistema nervoso central (SNC), havendo evidências que a Doença de Parkinson poderia, ao provocar degeneração destas vias, dentre outras alterações no sistema nervoso central, servir como fator de proteção para enxaqueca.

Unitermos. Cefaleia, Transtornos de Enxaqueca, Doença de Parkinson, Dopamina, Receptores Dopaminérgicos.

Citaçáo. Vilaça CO, Leite MAA, Souza JA, Pereira JS, Orsini M. Seria a Doença de Parkinson Fator Protetor da Enxaqueca?

\begin{abstract}
Objective. Make a review on the involvement of dopaminergic pathways in migraine and discuss the hypothesis that Parkinson's disease (PD), causing degeneration of dopaminergic pathways, could serve as a protective factor for Migraine. Method. We performed a Non-systematic review of articles using the keywords: "dopamine", "migraine" and "Parkinson Disease". Articles with the combination of these keywords in the title were preferred. We used to search the PubMed and Lilacs database. Results. We choose 32 original articles, 6 review articles and one manual. Conclusion. Migraine is characterized by a state of increased dopaminergic activity in the central nervous system (CNS) with evidence that Parkinson's disease, by causing degeneration of these pathways, among other changes in the central nervous system, serve as a protective factor for migraine.
\end{abstract}

Keywords. Headache, Migraine Disorders, Parkinson Disease, Dopamine, Dopaminergic Receptors.

Citation. Vilaça CO, Leite MAA, Souza JA, Pereira JS, Orsini M. Is Parkinson's Disease protective factor for migraine?

\footnotetext{
Trabalho realizado no Serviço de Pós-graduaçáo em Neurologia/Neurociências da Universidade Federal Fluminense (UFF), Niterói-RJ, Brasil.

1.Neurologista, Prefeitura Municipal de Duque de Caxias, Caxias-RJ, Brasil. Mestrando do Programa de pós-graduação em Neurologia/Neurociências da Universidade Federal Fluminense, Niterói-RJ, Brasil.

2.Neurologista, Doutor em Neurologia, Professor Adjunto de Neurologia da Universidade Federal Fluminense (UFF). MMC/Divisão de Neurologia. Setor de Desordens do Movimento da UFF, HUAP. Programa de pós-graduaçáo em Neurologia/Neurociências, UFF, Niterói-RJ, Brasil.

3.Neurologista, Doutor em Neurologia, Professor Adjunto de Neurologia da Universidade Federal Fluminense (UFF). MMC/Divisão de Neurologia. Setor de Transtornos Cognitivos da Universidade Federal Fluminense da UFF, HUAP. Programa de pós-graduação em Neurologia/Neurociências, UFF. Niterói-RJ, Brasil.

4.Neurologista, Doutor em Neurologia, Professor Associado de Neurologia da Universidade do Estado do Rio de Janeiro. Setor de Desordens do Movimento da UERJ, HUPE, Rio de Janeiro-RJ, Brasil. Programa de pós-graduação em Neurologia/Neurociências, UFF. Niterói-RJ, Brasil.

5.Médico, Doutor em Neurologia. Professor do Programa de pós-graduação em Neurologia/Neurociências, UFF. Niterói-RJ, Brasil. Programa de Mestrado em Ciências da Reabilitação - Centro Universitário Augusto Motta - UNISUAM, Rio de Janeiro-RJ, Brasil.
} 


\section{INTRODUÇÃO}

A enxaqueca ou migrânea é uma doença crônica que acomete indivíduos de ambos os gêneros, de todas as faixas etárias e etnias. Encontra-se entre as afecçóes neurológicas mais frequentes, afetando cerca de 15\% da população adulta no Brasil ${ }^{1}$. Embora possua letalidade desprezível, 50\% dos pacientes manifestam incapacidade funcional moderada a grave durante as crises. A enxaqueca se caracteriza clinicamente por crises de cefaleia, mais comumente pulsáteis e unilaterais, frequentemente de forte intensidade, agravadas por atividades cotidianas, fonofobia, fotofobia e/ou náuseas com ou sem vômitos. As crises costumam durar entre 4 a 72 horas sem tratamento ${ }^{2}$.

A doença de Parkinson (DP) é definida como uma doença neurodegenerativa do sistema nervoso caracterizada clinicamente por bradicinesia e ao menos um dos seguintes três sinais: o tremor de repouso, a rigidez e, o de surgimento mais tardio, a instabilidade postural (ineficiência dos mecanismos de manutenção da postura e equilíbrio) ${ }^{3}$. Acomete geralmente indivíduos acima dos 40 anos de idade. Seu início é geralmente insidioso com sinais unilaterais ou assimétricos. Apesar de ser definida como uma doença decorrente da lesão dos neurônios dopaminérgicos da parte compacta da substância negra do mesencéfalo ${ }^{3}$, existe também degeneração de outras regióes do SNC e do sistema nervoso periférico (SNP). Possui como aspectos histopatológicos mais relevantes a rarefação neuronal e a presença de inclusôes citoplasmáticas neuronais conhecidas como Corpos de Lewy contendo agregados proteicos compostos principalmente pela $\alpha$-sinucleína ${ }^{4}$.

A dopamina (DA) é uma amina que atua como neurotransmissor no SNC e SNP. Deriva do aminoácido tirosina e participa de diversos processos bioquímicos cerebrais. A DA é formada a partir da tirosina e a velocidade de sua síntese depende da hidroxilação catalisada pela enzima tirosina hidroxilase 5 . No cérebro humano, a dopamina age em diversas vias neuronais relacionadas ao comportamento, à memória, modulação da resposta a estímulos dolorosos, à harmonização dos movimentos e à produção de leite ${ }^{6}$. São reconhecidos, no SNC, cinco receptores dopaminérgicos, divididos em dois grupos cuja numeração representa a ordem em que foram desco- bertos: D1 (D1 e D5) e D2 (D2, D3, D4). No sistema nervoso periférico, a DA atua em algumas vias, tais como aquelas que regulam a peristalse do trato gastrointestinal e a manutenção do tono vascular ${ }^{6}$.

O objetivo do presente artigo é realizar uma revisão não sistemática sobre o papel da dopamina nos mecanismos da enxaqueca e discutir a hipótese na qual pacientes com enxaqueca, ao desenvolverem Doença de Parkinson, melhoram do quadro enxaquecoso ${ }^{7,8}$.

\section{MÉTODO}

Para a realização da presente atualização foram utilizadas as bases de dados PubMed e Lilacs, no período compreendido entre janeiro de 1992 a agosto de 2012. Realizamos revisão não sistemática de artigos, com metodologia do tipo estudos de coorte, descritivos e experimentais de caso único e de série de casos, além de relatos de caso (opinião de experts) e revisôes. Utilizamos para a busca os unitermos: "dopamine", "migraine" e "Parkinson Disease". Priorizou-se artigos que contivessem a associação desses unitermos no título. Alguns artigos foram escolhidos baseando-se no número de citações e pela relevância na discussão dos mecanismos dopaminérgicos envolvidos na enxaqueca, não sendo adotado nenhum critério específico para exclusão dos artigos. $\mathrm{O}$ estudo foi realizado no Serviço de Pós-graduação em Neurologia/Neurociências da Universidade Federal Fluminense (UFF). Como resultado Foram escolhidos 32 artigos originais, 6 artigos de revisão e um manual abordando o tema.

\section{DISCUSSÃo}

A enxaqueca figura entre as doenças mais frequentes da neurologia. Somada a alta prevalência, a doença é muito incapacitante, um dia de crise grave de enxaqueca equivale, em termos de limitaçôes, por exemplo, a um dia na vida de um tetraplégico (OMS) ${ }^{9}$. Quando respondem a questionários sobre qualidade de vida, indivíduos com enxaqueca possuem resultados piores do que aquelas com doenças muito debilitantes, tais como: depressão, osteoartrite, diabetes e hipertensão ${ }^{10}$. A enxaqueca se caracteriza clinicamente por crises de cefaleia, mais comumente pulsáteis e unilaterais, frequentemente de forte intensidade, agravadas por atividades cotidianas, fono e/ou fotofobia 
e/ou fortes náuseas com ou sem vômitos. As crises costumam durar entre 4 a 72 horas sem tratamento. A crise de dor pode ser precedida por manifestaçóes neurológicas de origem cortical (aura migranosa), durando entre 5 a 60 minutos, estando as alteraçôes visuais como defeitos campimétricos e escotomas entre as mais comuns ${ }^{2}$. Também os pródromos podem antecipar a crise de dor. Estes são caracterizados por sintomas que podem preceder a cefaleia da crise em até 48 horas sendo caracterizados por alteraçôes do humor (irritabilidade ou depressão), hipoatividade ou hiperatividade, fadiga, bocejos repetidos, alteraçôes gastrointestinais (diarréia ou constipação) e rigidez ou dolorimento muscular ${ }^{11}$.

Dentre as diversas teorias sobre a patogênese da enxaqueca, sugere-se que decorra da hiperexcitabilidade do córtex cerebral nos migranosos, resultando em episódios recorrentes de cefaleia e sintomas associados ${ }^{12}$. Não se sabe ao certo qual o mecanismo responsável pelo início das crises de enxaqueca, dos pródromos, da aura e da cefaleia. As hipóteses levam em consideração fatores vasculares, neurogênicos, bioquímicos, imunológicos e eletroquímicos, sem, no entanto, haver uma teoria definitiva ${ }^{13}$. Levando-se em conta apenas a teoria bioquímica da enxaqueca e a participação dos neurotransmissores, é frequente o destaque da serotonina (5-HT). Estudos na década de 60 demonstraram, na urina de voluntários com enxaqueca, aumento da excreção de seus metabólitos tal qual o ácido 5-hidroxi-indolacético (5-HIAA). A partir daí vários trabalhos se sucederam mostrando sua participação na crise de enxaqueca ${ }^{14}$. Entretanto, outros neurotransmissores, como a dopamina, têm sido relacionados à enxaqueca.

\section{Dopamina e Sensibilizaçáo Central da Enxaqueca}

Estudo concluiu pela existência de receptores dopaminérgicos no núcleo do trato espinhal do nervo do trigêmeo $(\mathrm{V})^{15}$. Essa região representa uma importante área relacionada à ativação de vias dolorosas centrais da enxaqueca e ao processo de sensibilização dolorosa central. Encontra-se envolvida na gênese da alodinia do couro cabeludo verificada em pacientes com enxaqueca crônica $^{15,16}$.

Verificou-se no hipotálamo a existência de uma região nomeada área A11, conectada, por meio de vias dopaminérgicas, ao corno dorsal da medula e ao núcleo do trato espinhal do nervo trigêmeo. É provável que tal região module as vias aferentes trigeminais e consequentemente o processo de dor nas crises e a sensibilizaçáo central da enxaqueca ${ }^{16}$. Hipoatividade de neurônios dopaminérgicos nesta via estariam ligadas a fisiopatologia da síndrome das pernas inquietas e explicaria porque há melhora desta condição clínica após tratamento com levodopa ou agonistas dopaminérgicos como o pramipe$\mathrm{xol}^{16}$. Deve-se ressaltar também que há maior prevalência de pernas inquietas em pacientes com enxaqueca ${ }^{17}$. Neste caso, contraditoriamente, apesar da enxaqueca caracterizar-se por um estado de aumento de atividade dopaminérgica, lesão na área A11, embora cause um estado hipodopaminérgico no eferente medular responsável pela clínica das pernas inquietas, causa um aumento do disparo neuronal na região do complexo trigeminocervical do trigêmeo $(\mathrm{V})$, levando ao estado de hipersensibilidade da enxaqueca $^{18}$.

\section{Dopamina, Sistema límbico e Enxaqueca}

Episódios de mudanças de humor e alteraçóes do apetite, notados como pródromos de crises de enxaqueca, decorrem de alteraçóes nos receptores dopaminérgicos durante os pródromos da crise. O Bocejo é um comportamento controlado por receptores $\mathrm{D}_{2}$ de neurônios ocitocinérgicos do núcleo periventricular do hipotálamo e sua ativação leva a liberação de ocitocina responsável pelo bocejo ${ }^{19}$. Embora não faça parte dos critérios de enxaqueca, a disosmia ou osmofobia, que comumente ocorre durante as crises ou no período de aura, pode estar associada à hipersensibilidade de receptores dopaminérgicos nos neurônios do bulbo olfatório ${ }^{19,20}$.

\section{Receptores Dopaminérgicos, Metabolismo da Dopa- mina e Enxaqueca}

Observou-se em determinados grupos de indivíduos com enxaqueca, variaçóes nos genes dos receptores de dopamina (subtipo $\mathrm{D}_{2}$ ), sendo que alguns alelos estariam ligados a hipersensibilidade dopaminérgica ocorrida na enxaqueca com aura ou sem aura ${ }^{21,22}$.

A crise de enxaqueca poderia ser decorrente do aumento de DA nas fendas sinápticas. Dentre os mecanismos reguladores dos níveis de DA na fenda sináptica 
está a diminuição da atividade da enzima dopamina beta-hidroxilase, que tem como função catalisar a transformação de DA em noradrenalina (NA), mantendo o balanço DA/NA no SNC. Mutaçóes no gene desta enzima já foram associadas ao aumento do risco de enxaqueca ${ }^{23,24}$. Alternativamente, os transportadores de dopamina pré-sinápticos (DAT), embora sejam os principais responsáveis pelos níveis de DA nas fendas sinápticas e portanto um importante alvo teórico para o risco de enxaqueca no caso de mutaçôes do gene DAT, tal associação nunca foi confirmada ${ }^{25,26}$.

As hipóteses de diminuição da atividade dopaminérgica decorrente das alteraçóes hormonais oriundas da senescência, especialmente a diminuição dos níveis de estrogênio verificadas nas mulheres com o fim de seu ciclo menstrual, poderia explicar a diminuição da frequência de crises de enxaqueca em pessoas idosas ${ }^{27}$. Neste contexto, o estrogênio, ao alterar a atividade da dopamina-hidroxilase e ao diminuir o número de receptores DAT pré-sinápticos poderia responder pelo aumento de DA nas sinapses, justificando parcialmente a maior incidência de enxaqueca nas mulheres no período reprodutivo ${ }^{28,29}$. Alternativamente, a progesterona, e não o estrogênio, poderia estar relacionado a enxaqueca menstrual. Neste caso a progesterona atuaria através da regulação dos níveis de DA na via tuberoinfundibular do hipotálamo, secundariamente regulando os níveis de prolactina, sendo que esta se encontra aumentada em pacientes com enxaqueca ${ }^{16}$.

\section{Dopamina e Sistema Nervoso Autônomo}

Verificou-se que o acometimento do sistema nervoso autônomo, manifestado através de náuseas e vômitos e frequentemente presente na crise de enxaqueca, pode decorrer de uma hiperatividade das vias dopaminérgicas existentes em estruturas do tronco cerebral, como os núcleos do trato solitário, núcleo dorsal do nervo vago e a área postrema bulbar, onde se localizam receptores $D_{2}$, $\mathrm{D}_{3}$ e $\mathrm{D}_{4}^{6}$.

A hipotensão ortostática, ocasionalmente causada pela crise de enxaqueca, parece ser devida à disfunção dopaminérgica da Substância Negra Mesencefálica e sua repercussão sobre a microcirculação encefálica com vasodilatação e hipoperfusão cerebral ${ }^{29}$. Em acréscimo, no sistema nervoso periférico, ocorre hiperexcitação de receptores dopaminérgicos localizados nas terminaçóes pré-ganglionares dos nervos simpáticos, havendo diminuição da liberação de noradrenalina (NA) por esses terminais, consequentemente agravando a hipotensão e podendo ocasionar inclusive episódios de síncope durante as crises 5 .

\section{Doença de Parkinson e Enxaqueca}

Segundo alguns poucos estudos, pacientes com enxaqueca melhoram progressivamente dessa doença, na medida em que, ao manifestarem DP, desenvolvem degeneraçấo das vias dopaminérgicas centrais ${ }^{7,8}$. Sabe-se que estudos com ressonância nuclear magnética funcional (fRNM) já demonstraram haver hiperativação da Substância Negra e do Núcleo Rubro, áreas ricas em neurônios dopaminérgicos no tronco cerebral (mesencéfalo), durante as crises de enxaqueca ${ }^{7}$. Ressalta-se que fármacos que agem nas vias serotoninérgicas, como o sumatriptano, pertencente à classe dos triptanos, e que notabiliza-se pela grande eficácia no tratamento da crise de enxaqueca, possui grande número de receptores nos neurônios dopaminérgicos da Substância Negra Mesencefálica ${ }^{7}$. Tais fatos poderiam justificar a melhora da enxaqueca em paciente com DP por degeneração destas vias, assim como a degeneração das vias dopaminérgicas responsáveis pela sensibilização central da dor na enxaqueca discutida anteriormente.

Sabe-se também que fármacos agonistas dopaminérgicos muito utilizados no tratamento da Doença de Parkinson (DP), tais como a apomorfina (não existente no Brasil) e o pramipexol, precipitam sintomas migranosos e até crises de enxaqueca em pacientes com DP e enxaqueca, aumentando a frequência de crises, como também tornando as dores mais intensas durante os ataques $^{7,8}$. Soma-se a isto o fato de pacientes com enxaqueca e DP apresentarem paraefeitos dos agonistas dopaminérgicos no tratamento da DP com menores doses em relação aos não enxaquecosos ${ }^{7,31}$. Como fator positivo na associação entre as duas doenças, pacientes com enxaqueca, devido à hipersensibilidade dopaminérgica, responderiam de forma satisfatória a doses menores de levodopa no tratamento da DP em relação a parkinsonianos sem enxaqueca $^{30}$. Alguns estudos sobre relação de enxaqueca e DP, contudo, carecem de número mais expressivo 
de pacientes e/ou de grupo controle ${ }^{8}$, ou utilizam como diagnóstico de enxaqueca a classificação anterior a atual de $2004^{7}$.

\section{Enxaqueca e Antagonistas da Dopamina}

Uma das maiores evidências relacionada à participação das vias dopaminérgicas na gênese da enxaqueca é o seu controle com o uso de antagonistas de receptores dopaminérgicos. Possuem essa característica especialmente os bloqueadores do receptor $\mathrm{D}_{2}$, tais como a flunarizina, haldol, clorpromazina, metoclopramida e domperidona. Outrossim, alguns figuram entre as drogas de primeira linha na profilaxia do surgimento dos ataques de enxaqueca, como a flunarizina, por exemplo ${ }^{5,33}$. Esse medicamento atua como profilático de enxaqueca, possivelmente através de sua ação antagonista de canal de cálcio, diminuindo o tônus da musculatura lisa vascular. Alternativamente sua ação na enxaqueca pode decorrer da ação bloqueadora $\mathrm{D}_{2}$, que é corroborada pelo fato de ser considerada um dos fármacos que mais ocasiona parkinsonismo medicamentoso na prática clínica ${ }^{32}$. O mesmo paraefeito, por mecanismo similar, é verificado com o uso do haloperidol e da clorpromazina ${ }^{34}$.

A clorpromazina mostra grande eficácia na crise enxaquecosa por via intravenosa (IV), com baixo índice de paraefeitos, excetuando-se hipotensão, mostrando-se como droga de baixo custo para uso na crise nos departamentos de emergência, porém sem as reaçōes distônicas agudas ou acatisias vistas com o haloperidol ${ }^{34-36}$. Outrora considerada um mero adjuvante no tratamento da crise migranosa, pelo efeito de atenuar náuseas e vômitos (reversão da gastroparesia) e, consecutivamente, facilitar a absorção de medicações analgésicas, a metoclopramida provavelmente diminui a cefalalgia da enxaqueca pela açáo nos receptores dopaminérgicos $\mathrm{D}_{2}$ centrais, independentemente de sua ação periférica5 ${ }^{5,33}$. Já a domperidona, por não atravessar a barreira hematoencefálica, possui apenas ação nos receptores periféricos $\mathrm{D}_{2}$ no $\mathrm{SNP}$, atuando nas náuseas e vômitos, porém sem ação na dor. Entretanto possivelmente aborta a crise de enxaqueca se administrado durante a fase prodrômica ${ }^{5}$. Aqui, a domperidona de forma interessante serve de demonstrativo entre as teorias dopaminérgicas atuantes na enxaqueca e DP, já que esta droga, além de seu efeito na enxaqueca, interessantemente parece atuar também na hipotensão, náuseas e vômitos de pacientes parkinsonianos em uso de levodopa ${ }^{37}$. No caso da hipotensão pode haver, como já citado, inibição dos receptores dopaminérgicos pré-sinápticos nos gânglios simpáticos destes pacientes. Existem relatos isolados de outras drogas antagonistas dopaminérgicas de uso menos frequente no Brasil que também melhorariam quadros enxaque $\cos ^{38}$. Não se pode esquecer, contudo, que muitas destas drogas possuem atividade em outros receptores do SNC e SNP que não os dopaminérgicos, o que pode em parte ser responsável pelos seus efeitos terapêuticos ${ }^{32,39}$.

\section{CONCLUSÃO}

A Enxaqueca está entre as doenças mais frequentes e incapacitantes da neurologia. $\mathrm{O}$ conhecimento das várias fases da doença assim como dos mecanismos propostos para a sua gênese são fundamentais para seu tratamento eficaz e desenvolvimento de novas terapias farmacológicas. Neste contexto, a Doença de Parkinson, ao provocar a degeneração de vias dopaminérgicas do SNC, pode servir como fator de proteção para enxaqueca, uma vez que essa se caracteriza por um estado de aumento da atividade dopaminérgica no SNC.

\section{REFERÊNCIAS}

1.Queiroz LP, Peres MFP, Piovesan EJ, Kowacs F, Ciciarelli MC, Souza JA, et al. A nationwide population-based study of migraine in Brazil. Cephalalgia 2009;29:642-9.

http://dx.doi.org/10.1111/j.1468-2982.2008.01782.x

2.Headache Classification Committee of the International Headache Society. The International Classification of Headache Disorders, 2nd edn. Cephalalgia 2004;24:1-160.

3.Hughes AJ, Daniel SE, Kilford L, Lees AJ. Accuracy of clinical diagnosis of idiopathic Parkinson's disease: a clinicopathological study of 100 cases. J Neurol Neurosurg Psychiatry 1992;55:181-4.

http://dx.doi.org/10.1136/jnnp.55.3.181

4.Del Tredici K, Rüb U, De Vos RA, Bohl JR, Braak H. Where Does Parkinson Disease Pathology Begin in the Brain? J Neuropathol Exp Neurol 2002;61:413-26.

5.Peroutka SJ. Dopamine and migraine. Neurology 1997;49:650-6.

http://dx.doi.org/10.1212/WNL.49.3.650

6.Akerman S, Goadsby PJ. Dopamine and migraine: biology and clinical implications. Cephalalgia 2007;27:1308-14.

http://dx.doi.org/10.1111/j.1468-2982.2007.01478.x

7.Barbanti P, Fabbrini G, Vanacore N, Rum A, Lenzi G, Meco G, et al. Dopamine and migraine: does Parkinson's disease modify migraine course? Cepha- 
lalgia 2000;20:720-3.

8.Van Hilten JJ. The migraine-dopamine link: do migraine and Parkinson's disease coexist? Clin Neurol Neurosurg 1992;94:S168-70.

9.Murray CJL, Lopez AD. The Global Burden of Disease: a comprehensive assessment of mortality and disability from diseases, injuries, and risk factors in 1990 and projected to 2020. Cambridge, Harvard University Press on behalf of the World Health Organization and the World Bank, 1996; p.11.

10.Osterhaus JT, Townsend RJ, Gandek B, Ware JE. Measuring the Functional Status and Well-Being of Patients with Migraine Headache. Headache 1994; 34:337-43.

http://dx.doi.org/10.1111/j.1526-4610.1994.hed3406337.x

11.Evans RW. Mannix L K Expert Opinion. Triptans for Migraine Prodrome. Headache 2002;42:83-4.

http://dx.doi.org/10.1046/j.1526-4610.2002.02018.x

12.Welch KMA. Contemporary concepts of migraine pathogenesis. Neurology 2003;61:S2-8.

13.Izzati-Zade K F. The Role of Serotonin in the Pathogenesis and Clinical Presentations of Migraine Attacks. Neurosci Behav Physiol 2008;38:501-5. http://dx.doi.org/10.1007/s11055-008-9008-3

14.Panconesi A.Serotonin and migraine: a reconsideration of the central theory. J Headache Pain 2008;9:267-76.

http://dx.doi.org/10.1007/s10194-008-0058-2

15.Gladstone JP. Dopamine and migraine: trigeminovascular nociception genetics and therapeutics. Cephalalgia 2007; 27:1315-20.

http://dx.doi.org/10.1111/j.1468-2982.2007.01479.x

16.Charbit AR, Akerman S, Goadsby PJ. Dopamine: what's new in migraine? Curr Opin Neurol 2010; 23:275-81.

17.Rhode AM, Hösing VG, Happe S, Biehl K, Young P, Evers S. Comorbidity of migraine and restless legs syndrome a case-control study. Cephalalgia, 2007;27:1255-60.

http://dx.doi.org/10.1111/j.1468-2982.2007.01453.x

18.Charbit AR, Akerman S, Holland PR, Goadsby PJ. Neurons of the dopaminergic/calcitonin gene-related peptide A11 cell group modulate neuronal firing in the trigeminocervical complex: an electrophysiological and immunohistochemical study. J Neurosci. 2009 Oct 7;29:12532-41.

19.Palmas MA, Cherchi A, Stochino E, Congiu D, Del Zompo M. Dopamine genes and migraine. J Headache and Pain 2000;1:S153-6.

20.Cave J, Baker H. Dopamine Systems in the Forebrain. Adv Exp Med Biol 2009;651:15-35.

http://dx.doi.org/10.1007/978-1-4419-0322-8 2

21.Peroutka SJ, Wilhoit T, Jones K. Clinical susceptibility to migraine with aura is modified by dopamine D, receptor (DRD2) NcoI alleles. Neurology 1997;49:201-6.

http://dx.doi.org/10.1212/WNL.49.1.201

22.Del Zompo M, Cherchi A, Palmas MA, Ponti M, Bocchetta A, Gessa GL, et al. Association between dopamine receptor genes and migraine without aura in a Sardinian sample. Neurology 1998;58:781-6.

http://dx.doi.org/10.1212/WNL.51.3.781

23.Lea RA, Dohy A, Jordan K, Quinlan S, Brimage PJ, Griffiths LR. Evidence for allelic association of the dopamine b-hydroxylase gene (DBH) with susceptibility to typical migraine. Neurogenetics 2000;3:35-40.

24.Fernandez F, Colson N, Quinlan S, MacMillan J, Lea RA, Griffiths LR. Association between migraine and a functional polymorphism at the dopamine $\beta$-hydroxylase locus. Neurogenetics 2009;10:199-208.

http://dx.doi.org/10.1007/s10048-009-0176-2
25.McCallum LK, Fernandez F, Quinlan S, Macartney DP, Lea RA, Griffiths LR. Association study of a functional variant in intron 8 of the dopamine transporter gene and migraine susceptibility. Eur J Neurol 2007; 14:706-7. http://dx.doi.org/10.1111/j.1468-1331.2007.01800.x

26.Karwautz A, Campos de Sousa S, Konrad A, Zesch HE, Wagner G, Zormann A,et al. Family-based association analysis of functional VNTR polymorphisms in the dopamine transporter gene in migraine with and without aura. J Neural Transm 2008;115:91-5.

http://dx.doi.org/10.1007/s00702-007-0799-0

27.Haan J, Hollander J, Ferrari MD. Migraine in the elderly: a review. Cephalalgia 2006;27:97-106.

http://dx.doi.org/10.1111/j.1468-2982.2006.01250.x

28.Martin VT, Behbehani M. Ovarian Hormones and Migraine Headache: Understanding Mechanisms and Pathogenesis - Part I. Headache 2006;46:323.

http://dx.doi.org/10.1111/j.1526-4610.2006.00309.x

29. Watson CS, Alyea RA, Hawkins BE, Thomas ML, Cunningham KA, Jakubas AA. Estradiol effects on the dopamine transporter - protein levels, subcellular location, and function. J Mol Signal 2006;1:5.

http://dx.doi.org/10.1186/1750-2187-1-5

30.Krimer LS, Muly EC 3rd, Williams GV, Goldman-Rakic PS. Dopaminergic regulation of cerebral cortical microcirculation. Nature Neuroscience 1998;1:286-9.

http://dx.doi.org/10.1038/1099

31.Cubo E, Kompoliti K, Leurgans SE, Raman R. Dopaminergic Hypersensitivity In Patients With Parkinson Disease And Migraine. Clin Neuropharmacol 2004;27:30-2.

http://dx.doi.org/10.1097/00002826-200401000-00009

32.McGeeney BE. Dopamine Antagonists and Migraine. Drug Dev Res 2007;68:341-5.

http://dx.doi.org/10.1002/ddr.20198

33.Cupini LM, Troisi E, Placidi F, Diomedi M, Silvestrini M, Argiro G, et al. Does the antimigraine action of flunarizine involve the dopaminergic system? A clinical-neuroendocrinological study. Cephalalgia 1999;19:27-31.

http://dx.doi.org/10.1111/j.1468-2982.1999.1901027.x

34.Honkaniemi J, Liimatainen S, Rainesalo S, Sulavuori S. Haloperidol in the Acute Treatment of Migraine: A Randomized, Double-Blind, Placebo-Controlled Study. Headache 2006;46:781-7.

http://dx.doi.org/10.1111/j.1526-4610.2006.00438.x

35.Bigal ME, Bordini CA, Speciali JG. Intravenous chlorpromazine in the emergency department treatment of migraines: A Randomized Controlled Trial. JEM 2002;23:141-8.

36.Da Costa AR, Monzillo PH, Sanvito WL. Uso da clorpromazina para tratamento de cefaléia no serviço de emergência. Arq Neuropsiquiatr 1988;66(3B):565-8.

37.Lang AE. Acute Orthostatic Hypotension When Starting Dopamine Agonist Therapy in Parkinson Disease: The Role of Domperidone Therapy. Letters to the Editor. Arch Neurol 2001;58:835.

38.Piovesan EJ, Lange MC, Teive HAG, Tatsui CE, Kowacs PA, Piovesan LM, et al. Mudança no padrão biológico da migrânea com aura após utilização da tetrabenazina. Arq Neuropsiquiatr 2000;58(2B):566-71.

39.Mascia A, Afra J, Schoenen J. Dopamine and migraine: a review of pharmacological, biokhemical, neurophysiological, and-therapeutic-data. Cephalalgia 1998; 18:174-82.

http://dx.doi.org/10.1046/j.1468-2982.1998.1804174.x 